\title{
Study on a hypothetical replacement of nuclear electricity by wind power in Sweden.
}

\author{
F. Wagner ${ }^{1}$ and E. Rachlew ${ }^{2}$ \\ ${ }^{1}$ Max-Planck-Institut für Plasmaphysik, Greifswald, Germany \\ ${ }^{2}$ Department of Physics, Royal Institute of Technology, SE-10696 Stockholm, Sweden
}

fritz.wagner@ipp.mpg.de

\begin{abstract}
The Swedish electricity supply system benefits strongly from the natural conditions which allow a high share of hydroelectricity. A complete supply is, however, not possible. Up to now, nuclear power is the other workhorse to serve the country with electricity. Thus, electricity production of Sweden is basically $\mathrm{CO}_{2}$-free and Sweden has reached an environmental status which others in Europe plan to reach in 2050. Furthermore, there is an efficient exchange within the Nordic countries, Nordpol, which can ease possible capacity problems during dry cold years. In this study we investigate to what extent and with what consequences the base load supply of nuclear power can be replaced by intermittent wind power. Such a scenario leads unavoidably to high wind power installations. It is shown that hydroelectricity cannot completely smooth out the fluctuations of wind power and an additional back-up system using fossil fuel is necessary. From the operational dynamics, this system has to be based on gas. The back-up system cannot be replaced by a storage using surplus electricity from wind power. The surplus is too little. To overcome this further strong extension of wind power is necessary which leads, however, to a reduction of the use of hydroelectricity if the annual consumption is kept constant. In this case one fossil-free energy form is replaced by another, however, more complex one. A mix of wind power at $22.3 \mathrm{GW}$ plus a gas based back-up system with $8.6 \mathrm{GW}$ producing together $64.8 \mathrm{TWh}$ would replace the present infrastructure with $9 \mathrm{GW}$ nuclear power producing $63.8 \mathrm{TWh}$ electricity. The $\mathrm{CO}_{2}$-emission increases to the double in this case. Pumped storage for the exclusive supply of Sweden does not seem to be a meaningful investment.
\end{abstract}

\section{Introduction}

The Swedish electricity supply is based on hydro-electricity, nuclear power, electricity import/export, electricity from other heat sources which are mostly based on bio-mass, from wind and to a small extent from not further specified sources. From Fig.1 it is seen that in the seventies the nuclear power was built up to be run as baseload and to eliminate the oil dependence, whereas hydropower could partly be baseload and partly load following dispatch (i.e. the variations in production and consumption for every moment). One consequence of this development has been that the electricity production has been largely free of carbon 
emission. The specific $\mathrm{CO}_{2}$ emission factor $\eta_{\mathrm{CO} 2}=0.023 \mathrm{kgCO}_{2} / \mathrm{kWh}-$ a quality only met in Europe by Switzerland and Norway.

Sweden's electricity consumption has been rising and it has one of the world's highest individual levels of consumption. Per capita electricity consumption was $13.400 \mathrm{kWh}$ in 2013. About $40 \%$ of domestic production is nuclear, and up to half hydro, depending on the season (affecting hydro potential). In 2013, Sweden generated $133.7 \mathrm{TWh}$ of which $63.8 \mathrm{TWh}$ (48\%) was from nuclear and 61.7 TWh (46\%) from hydro. Wind provided $10 \mathrm{TWh}$, biofuels \& waste $10.6 \mathrm{TWh}$, and various fossil fuels $5 \mathrm{TWh}$. The total capacity at the end of 2012 was 38 GWe. By law, grid operator Svenska Kraftnat must ensure about 2 GWe winter reserve capacity.

Electricity imports and exports with Finland, Norway, and Denmark (and lately with the Baltic countries, to Poland and to Germany thanks to new distribution lines) vary according to season, During the last few years Sweden has been net exporter of electricity, in total about 10-15 TWh per year. The Swedish distribution is presently divided into four regions of Sweden, the northern being where most hydro-power is produced and the southern where most of electricity is consumed and where the nuclear power is produced. The Swedish distribution net is interlinked with Nordpol, connecting the Nordic countries to a common market. In this analysis we do not consider how much the distribution net needs to be upgraded (rebuilt) to take care of the increased installations of intermittent production.

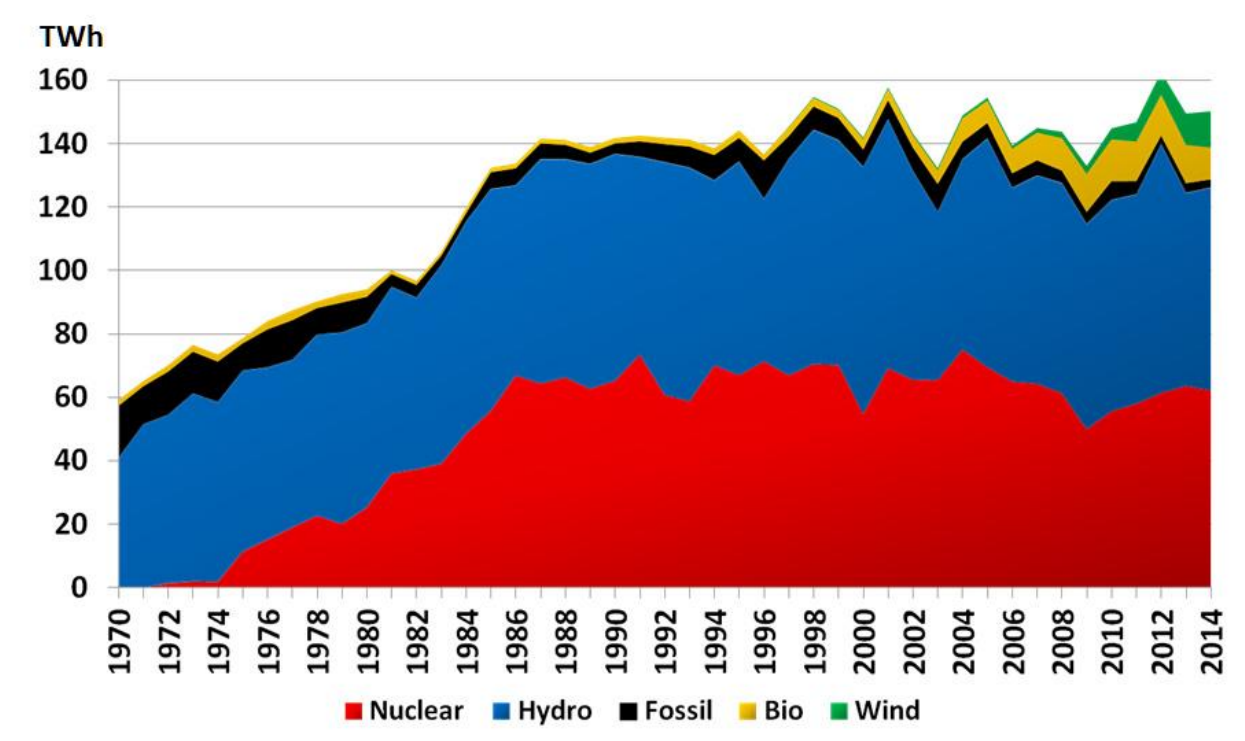

Källa: Energimyndigheten

Figure 1. The electricity production 1970 - 2014 with the build-up of nuclear power over a ten year period starting 1974 and then largely kept constant over thirty years. (Source: Energimyndigheten).

In 2015 decisions were made to close four older reactors by 2020, removing 2.7 GWe net. Sweden has a tax discriminating against nuclear power - now about 0.67 Euro cents/kWh, which makes up about one-third of the operating cost of nuclear power. Wind and biomass are 
subsidized by about three times that. Sweden also has a very high tax on $\mathrm{CO}_{2}$ emissions: $€ 110 /$ tons according to Energia.fi. Wind and biomass are generously subsidized with a certificate system agreed jointly with Norway.

The present situation in Sweden (spring 2016) is that one nuclear power station close to Copenhagen closed earlier (Barsebäck, closed in 1999 and 2005) and that the power companies have advertised to close four out of the ten remaining stations before the previously planned shut-down (2022). Furthermore, the companies have warned that the economic outcome for the remaining power stations might be too low with the present electricity prices, and taxes. There is presently a parliamentary commission working to find a broad political agreement for the Swedish electricity energy system beyond 2025. The commission should have a final answer by January $1^{\text {st }}, 2017^{1}$.

In this study we analyse the consequences of a hypothetical change in supply technology replacing the $\mathrm{CO}_{2}$-free nuclear generation, which represents a base-load supply by wind power, which is also $\mathrm{CO}_{2}$-free, however, intermittent and predictable only within limits.

The major questions addressed in this context are the capability of hydroelectricity to compensate the volatile nature of wind power and the specification of a back-up power system if hydroelectricity at the present level allows only partial compensation. The hydroelectricity power in Sweden is mainly generated by the large rivers in the north flowing into the Baltic see. This means that the power is generated by many power stations along the rivers enforcing joint operation between all of them to minimize losses. It is interesting to note that this is a situation similar for the hydroelectricity power in Switzerland while the situation in Norway is very different with a large part of the power from water magazines high in the mountains and high waterfalls enabling pumped storage.

The general procedure for the present analysis is described in [2] and applications for Germany, France, Italy and several European countries are given in [3-7]. Furthermore, recent studies on the gross wind situation in the European countries [7] have shown that further inter-countries distribution net connections can only partly take up the intermittent wind surplus simply because the European, and in particular, the northern European countries have a rather similar wind pattern. This is already evident in the present distribution limits occurring between Denmark, Sweden and Germany.

\begin{tabular}{|l|l|l|l|l|l|l|}
\hline Load & Wind & Water & Nuclear & Bio-mass & Others & Export \\
\hline 133.74 & 10.00 & 61.68 & 63.84 & 8.10 & 0.06 & 9.96 \\
\hline
\end{tabular}

Table 1. The different constituents to the electricity balance in 2013 are given. The units are TWh.

\footnotetext{
${ }^{1}$ www.energikommissionen.se
} 


\section{Procedure and assumptions}

In this study we use data for the load and the various supply sources from 2013. The data have been provided by Svenska Kraftnät [1] and are given in Table $1^{2}$. They are available in $1 \mathrm{~h}$ time steps.

Hydro-electricity is comprised of run-off and storage power. Both vary seasonally. Whereas nuclear power is rather constant through the year hydroelectricity is used to meet the variable load (see Fig. 2).

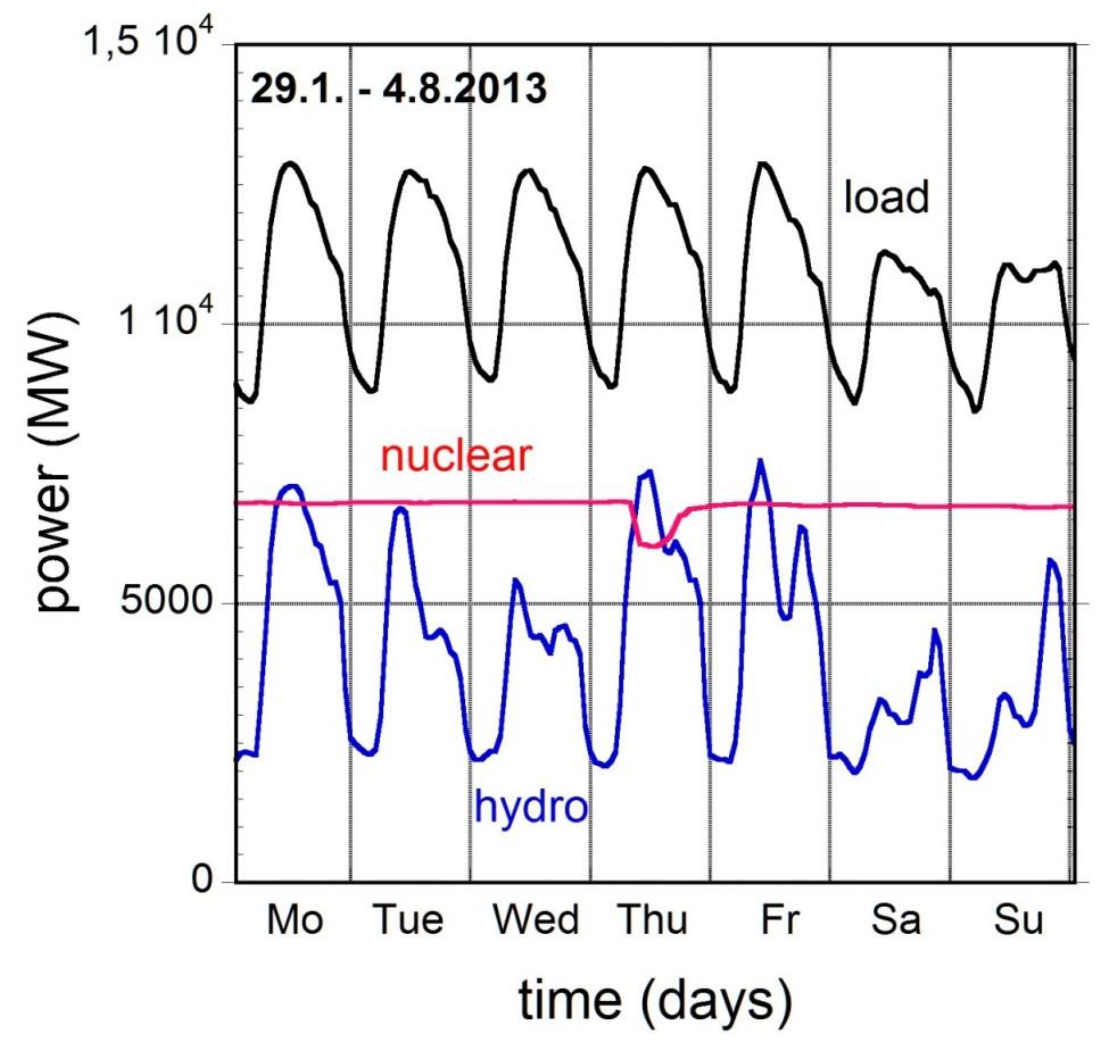

Figure 2. Daily variation of load and supply by non-CO $\mathrm{C}_{2}$ sources during a summer week.

To begin with, photovoltaic power (PV) is ignored in the main study as its contribution is still rather small and possibly will remain so also in the future. The main renewable energy source following hydroelectricity is wind power. At the end of 2013, $4.47 \mathrm{GW}$ have been installed. In the following, the wind power will be linearly scaled to higher values, the nuclear power correspondingly decreased up to the limit, where the annual contribution of nuclear energy is formally replaced. In order to be able to operate with constant installed wind power, the original data of 2013 have been corrected for the growth of wind power during the year. A linear growth has been assumed from the power available at the end of 2012 of $3.65 \mathrm{GW}$ to the value at the end of 2013. The energy to be harvested increased by this correction from 10.0 to $10.93 \mathrm{TWh}$.

\footnotetext{
${ }^{2}$ Different sources give slightly different figures.
} 
The following assumptions have been made: The load stays constant at the value given in table 1. It is further assumed that electricity from biomass will stay at the present level. Import and export are not considered. The target supply is what is called the reduced load (demand) which is constructed from the actual load data after the present level of electricity from biomass and the smaller contributions have been subtracted. It is assumed that they are provided as base-load supply at constant power. The annual energy of the reduced load is $125.54 \mathrm{TWh}$. This value has to be met by hydroelectricity at unchanged integral value $(61.68 \mathrm{TWh})$ and - if nuclear power is abandoned - by wind power together - if needed - with contributions from a back-up system which is not further specified at the moment.

The following questions are investigated:

i) How large has the installed wind power to be to meet together with hydroelectricity the reduced demand?

ii) Is a back-up system necessary in this case and if-so, what is the needed power and the dynamics of its operation (which could determine the system type required for back-up)?

iii) How much surplus is produced when the wind contribution is in excess of the reduced load and is it worth to save surplus energy in a storage to substitute backup?

iv) What are the operational conditions for hydroelectricity and is this form of operation acceptable for the system?

It is clear from the literature on hydroelectricity generation [8] that the supply system is a complex one because other demands apart from electricity production have to be considered (water supply, flood prevention, fishing and low water levels, recreation and environment...). The Swedish case is discussed in more detail in [9]. A major operational issue is the link between different storage power systems along one river which requires joint planning to avoid water spills and losses. A detailed study requires the consideration of each river system separately to assess the consequences of electricity production of a single hydro power station on those which are located further down on the basis of the travelling times of water waves. In order to minimize water losses a coherent operation of all stations along the river is necessary. This aspect will grow in importance when the task of meeting exactly the load will be aggravated in the future by additionally compensating wind power. In the present situation with little wind power the future short-term demand can be predicted with some reliability allowing to develop a strategy to minimise losses; this feature would be lost in case of compensating erratic and strongly fluctuating wind power.

Such a detail cannot be offered in an integral study like this one which is more intended to identify gross system features. In order to match the seasonal and operational conditions as best as possible, the operation of the hydropower system when compensating large amounts of wind power is subject to limits in the process of extrapolating the wind data. A trivial limit is that the annual hydroelectricity production of $61.68 \mathrm{TWh}$ which cannot be surpassed. It is assumed that all other limits are respected by three figures - the maximal power and the maximal and minimal power gradients. It is expected that the seasonal variation of the 
operational conditions of the hydro system is observed when these limits are defined for each day as established for 2013 and obeyed in the extrapolation toward larger wind contributions.

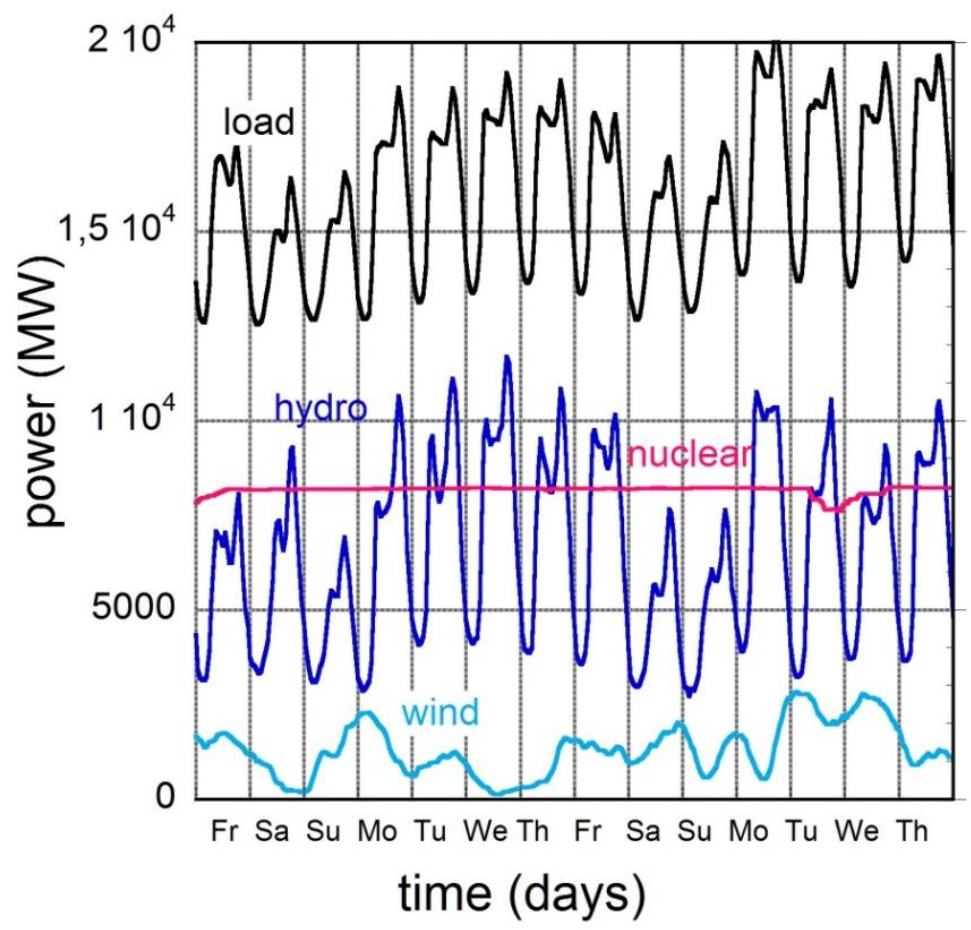

Figure 3a. Original situation of the load, hydroelectricity, nuclear and wind power in 2013 for the first two weeks in November 2013.

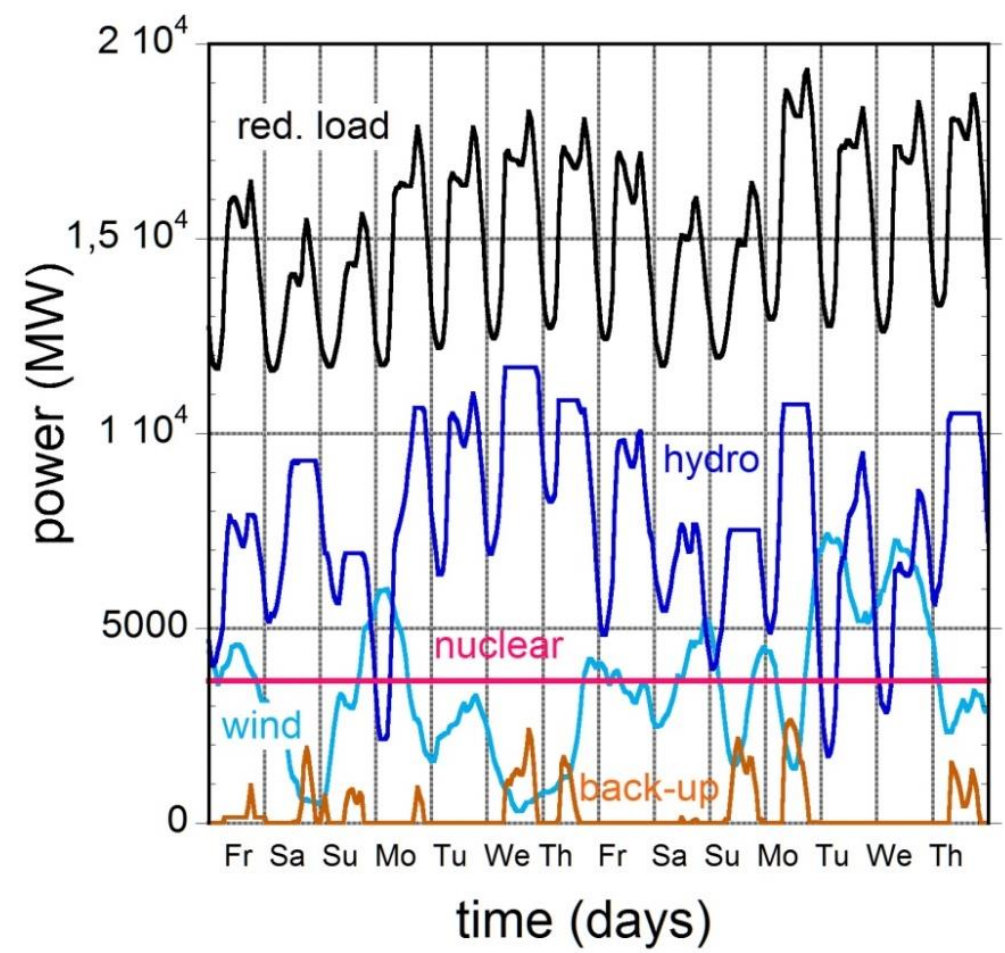

Figure $3 b$. Plotted is the reduced load along with the original nuclear power, whose contribution is halved. Plotted are also the necessarily increased wind contribution and the one from a back-up system. 


\section{Results}

Fig. 3a shows the load, nuclear- hydro-electricity -and wind power for the first two weeks in November for the original situation. The original load is mostly met by nuclear and hydro power as shown in Fig. 2. The daily variation of the power is covered by hydroelectricity. In the first step of our study, the nuclear output is halved from originally 63.84 TWh to 31.92 TWh. The wind power has to be increased from presently $4.47 \mathrm{GW}$ to $11.2 \mathrm{GW}$. The annual electricity production is kept constant at the level of the reduced load of $125 \mathrm{TWh}$.

The leading role in compensating the intermittency of wind power is left to hydroelectricity. In this case, no additional $\mathrm{CO}_{2}$ emission happens. The dynamics of the hydro system increases as can be seen in Fig. 3b. During many days, the power increases up to the limit of the respective day as described above. As hydroelectricity is thus limited, taken as a basic operational restriction, a back-up system is required to be able to fully meet the demand. Its action is also shown in Fig. 3b; it contributes in periods of maximal hydroelectricity production when nevertheless the reduced load cannot be met.

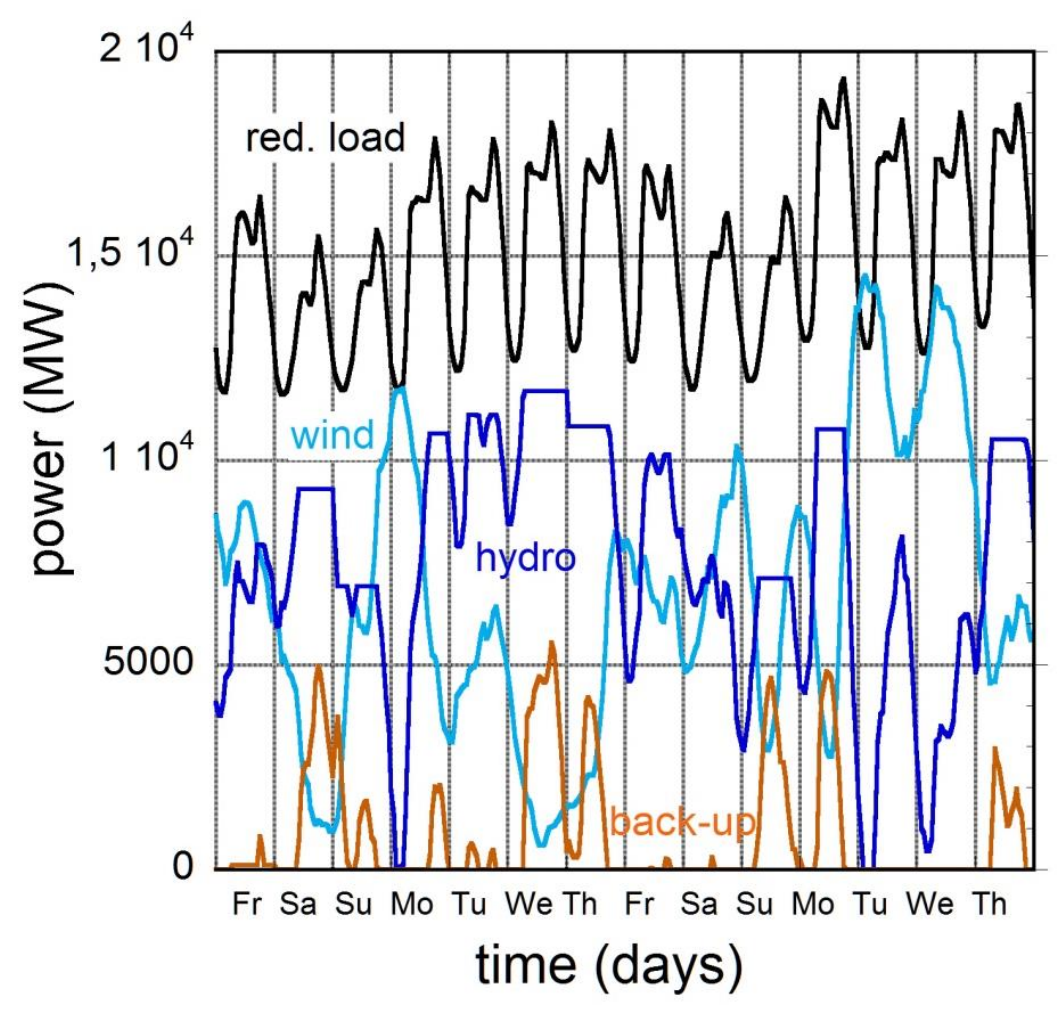

Figure 3c shows the case where nuclear power has totally been removed and replaced by power from wind and the back-up system.

Figure $3 \mathrm{c}$ shows the case where nuclear power has totally been removed and replaced by power from wind and the back-up system. The installed wind power is increased now to 22.3 GW a factor of 5 above the 2013 state of completion delivering $54.3 \mathrm{TWh}$. In phases of low demand, surplus energy can sum up to $0.58 \mathrm{TWh}$. More use has to be made of the back-up 
system specified with $8.6 \mathrm{GW}$ delivering $10.5 \mathrm{TWh}$ at a still low and uneconomic capacity factor of $11 \%$. To compare with, the nuclear power system produced with about the same installed power a factor of 6 more energy.

A specific feature of the hydro-electricity system is now the operation between the maximal power and no power at all (see Fig. 3c). The hydropower is delivered in a rather uneven form. The collective system operates for $3656 \mathrm{~h}$, for nearly half a year, at full power and for $380 \mathrm{~h}$ delivering nothing to the grid. It can be doubted whether a distributed hydro-system can safely and economically be operated in this form. In particular, the very large variations over a short time are definitely beyond the limits of the present hydro-system.

Next we address the dynamics of the back-up system. For the $100 \%$ case, a back-up system at the power level of the original nuclear power capacity is necessary. It is subject to strong operational dynamics as demonstrated by Fig. 4.

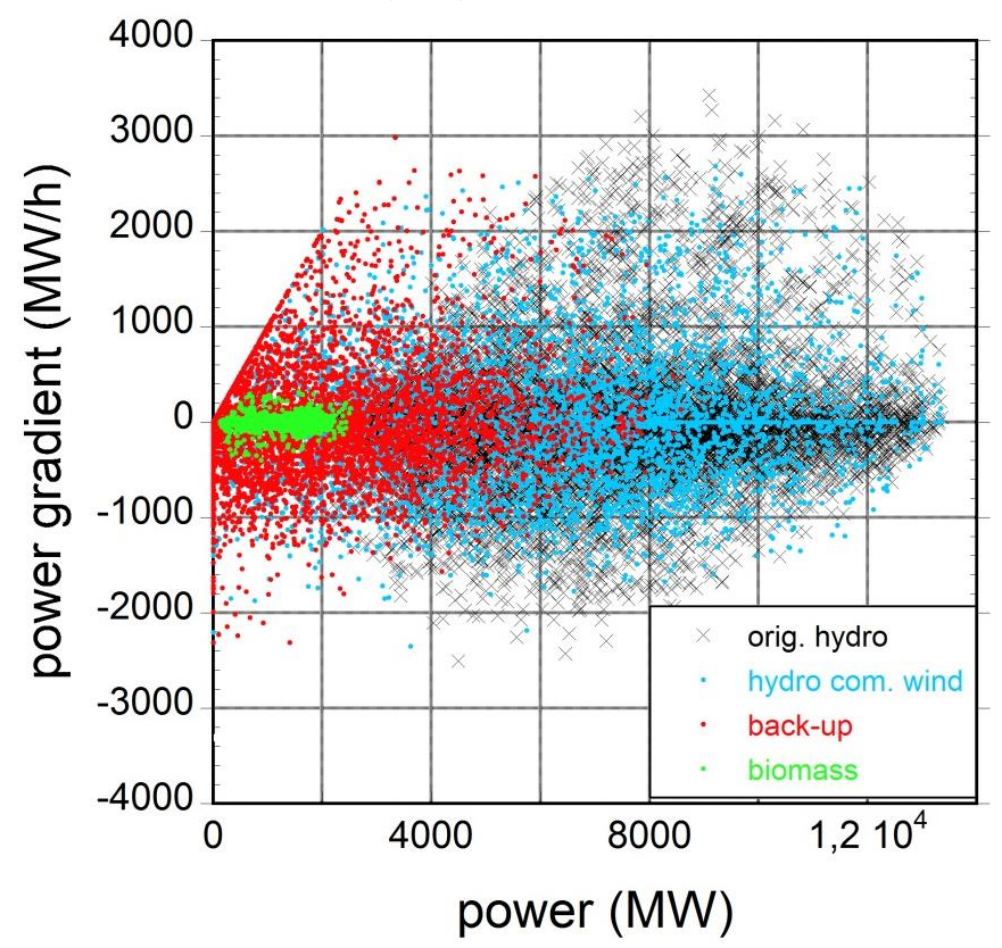

Figure 4. Plotted is the power gradient versus the respective power of the original 2013hydro and biomass data and the hydro- and back-up system when they fully compensate wind power. The terms are defined in the text.

The power gradient $\Delta \mathrm{p}_{\mathrm{i}}$ is defined by the step in power from $\mathrm{p}_{\mathrm{i}-1}$ to $\mathrm{p}_{\mathrm{i}}$ at time point $\mathrm{i}: \Delta \mathrm{p}_{\mathrm{i}}=\left(\mathrm{p}_{\mathrm{i}-}\right.$ $\left.1-p_{i}\right) / \Delta t . \Delta t$ is the time step of the data bank of $1 \mathrm{~h}$. The dynamics of the original hydroelectricity system (black crosses) when matching the load is shown for comparison.

Comparable excursions are obtained when hydroelectricity compensates wind power (blue dots) as it is given as boundary condition for the process dynamics. The variation of bioelectricity (green dots) is also shown. It is small indicating that biomass in its present extent cannot play a big role in smoothing wind power. Therefore, the bio-mass production was treated in this paper as baseload demand. Finally, the fluctuation level of the back-up system 
(red dots) is comparable to the one of the hydro-electricity system.

As the individual turbines of hydroelectricity can be regulated in a fast rate for a single unit, from 0 to $100 \%$ in about $10 \mathrm{~min}^{3}$, it is clear that the back-up system can only comprise of a gas turbine system, the next fastest technology. If nuclear power is replaced by wind the necessary back-up system - burning gas - would lead to an increase of the specific $\mathrm{CO}_{2}$ production of Sweden from 0.023 to $0.034 \mathrm{~kg} / \mathrm{kWh}$.

As can be seen in Figs. $3 \mathrm{~b}$ and 3c, the back-up power is needed specifically during high load periods. This implies that in a situation where wind replaces nuclear electricity, export during high demand periods is not possible because first there is the national need and secondly, the export would be based predominantly on fossil generation.

On the other hand, the back-up need during the day with a peak during mid-day evokes the question to what extent back-up power could be substituted by PV power. Rudimentary PV data have been provided in the data bank of Svenska Kraftnät and were scaled to a level where PV electricity can partially substitute back-up power. We discriminate between "useful" PV energy which can replace back-up energy and PV surplus energy which cannot be accommodated. A natural limit for the employment of PV power is reached when the "useful" fraction reaches $50 \%$ of the total produced PV energy and matches the PV surplus. With nearly $7.4 \mathrm{GW}$ installed PV power the back-up power can be reduced by merely $6 \%$. One has to conclude that the use of PV power, within the frame as discussed here at a fullload-hour of $716 \mathrm{~h}$ or a capacity factor of $8 \%$ is hardly worth the effort.

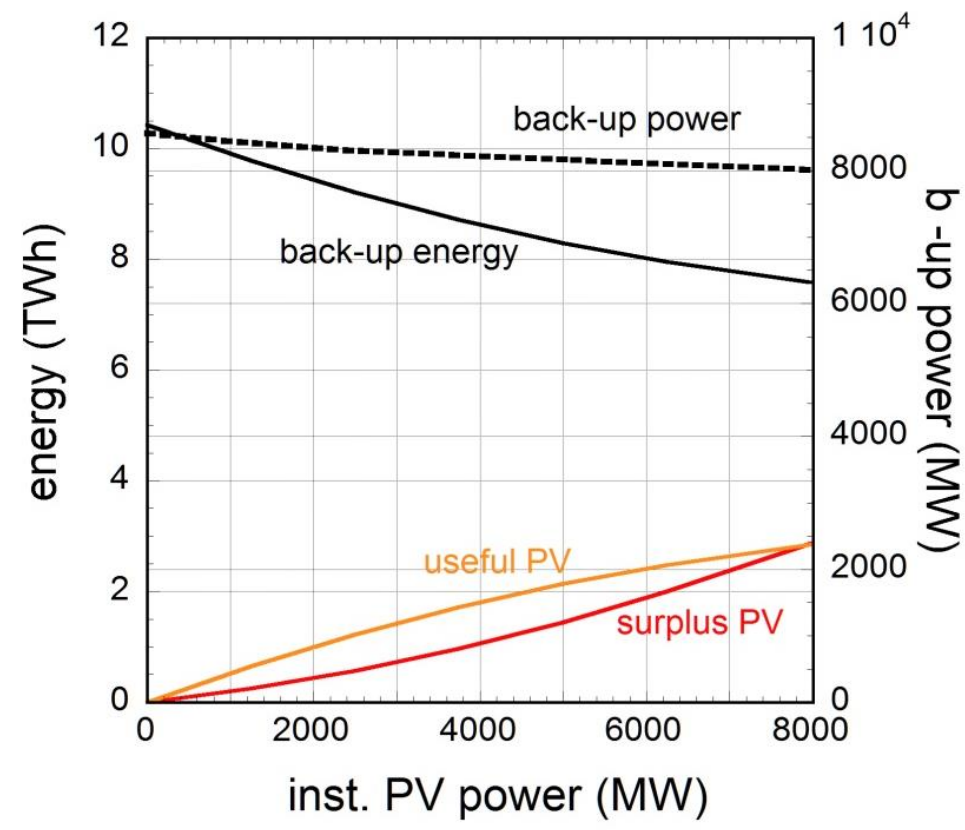

${ }^{3}$ The coherent operation of an integrated hydro-electricity system built along a single river does, however, not allow such response times. 
Figure 5 plots the reduction of the back-up energy and power versus the installed PV power. Also plotted is the variation of the useful PV and surplus PV energy up to the above mentioned limit where useful and surplus $P V$ energy are the same.

Another way to overcome a back-up system using fossil fuel is to employ storage, e.g. in the form of pumped storage. This does, however, not seem to be a practical way for the case of a $100 \%$ replacement of nuclear power by wind and the contributions from a back-up system. The smoothing effect of both hydro- and back-up electricity allows only a small surplus component to develop. For the $100 \%$ case as discussed above, the surplus energy is 0.58 TWh, only $6 \%$ of the necessary back-up energy. In order to utilise surplus energy in conjunction with storage requires increasing the surplus production and, for the ideal cases considered here (no losses), the surplus energy has to match the back-up energy.

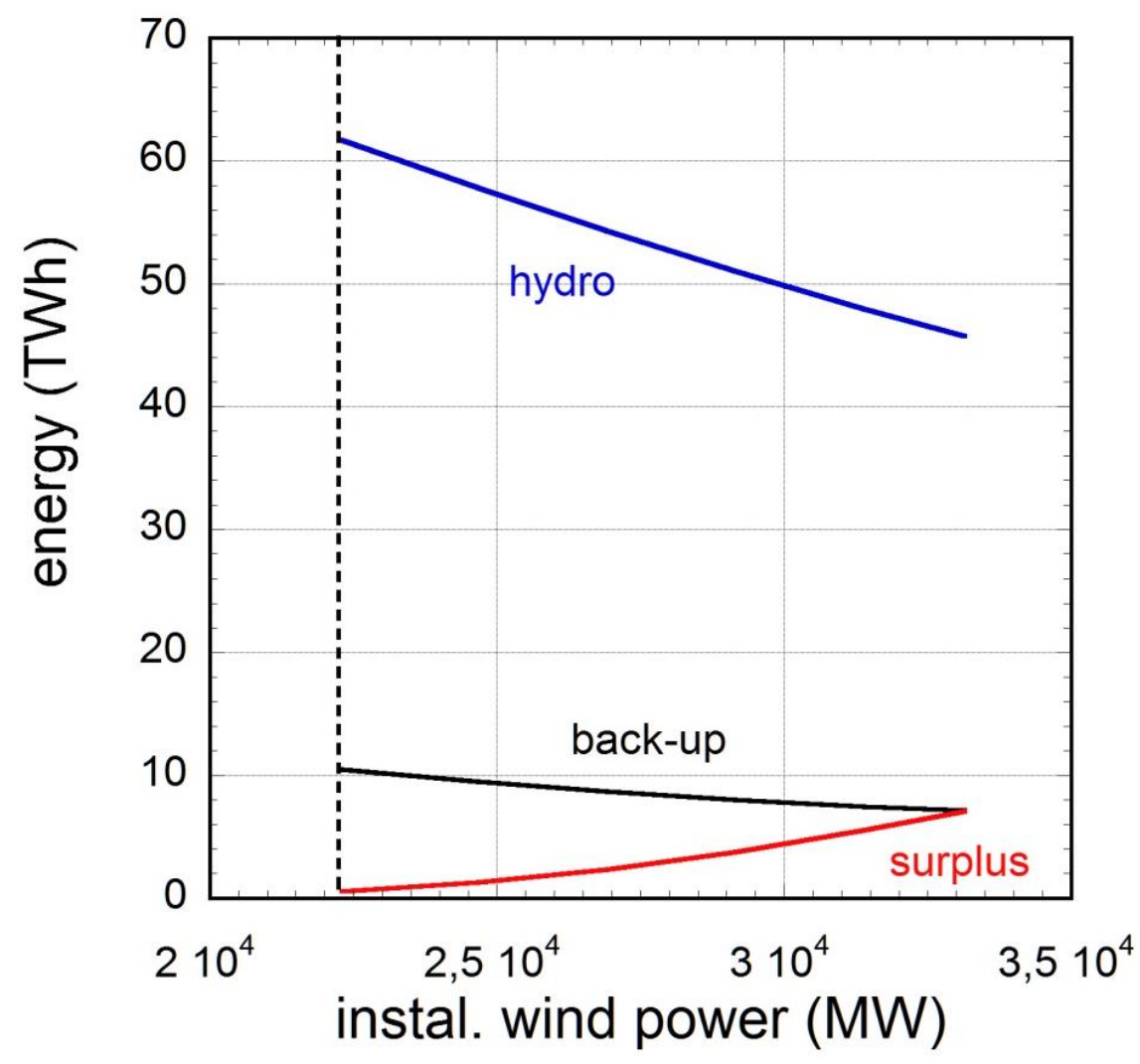

Figure 6. Plotted are the energies of the back-up system, of surplus and of the hydro system when the installed wind power is increased beyond the level of the 100\% case (dashed line). The curves stop when back-up and surplus energies are identical.

Fig. 6 shows the development of the annual energy production of the back-up system and of hydroelectricity and the surplus energy versus installed wind power beyond the $100 \%$ case (dashed vertical line) to intentionally increase surplus. With increasing wind power surplus energy increases and back-up energy gradually decreases. They meet at a wind installation of $33 \mathrm{GW}$. Under these conditions, ideal storage operation is possible (surplus = back-up energy). However, the increased wind contribution goes fully at the expense of hydro-electricity whose share decreases as shown in Fig. 6. As a consequence, one $\mathrm{CO}_{2}$-free supply form is replaced by a more complex one which additionally needs storage to make the system completely $\mathrm{CO}_{2}$-free. This scenario does not seem to be reasonable. From 
this point of view, there does not seem to be a major driving motive for Sweden to invest into pumped storage systems.

\section{Summary}

Fig. 7 summarises the scenarios where nuclear energy is replaced in steps by wind energy necessitating contributions from a fossil power station, most probably based on burning gas. The consequence is that the replacement of nuclear energy unavoidably leads to the use of fossil fuel and an increase in $\mathrm{CO}_{2}$ emission. The use of fossil power stations seems to be unavoidable and can be replaced neither by PV power nor by storage. Figure 7 plots the variation of installed wind, nuclear and back-up power if the annual nuclear energy contribution is reduced. The corner points of Fig. 7 are given by either the present situation where nuclear power with $9 \mathrm{GW}$ produces $63.8 \mathrm{TWh}$ electricity or, the other extreme, where a mix of wind power at $22.3 \mathrm{GW}$ plus a gas based back-up system with $8.6 \mathrm{GW}$ produces in total $64.8 \mathrm{TWh}$. The $\mathrm{CO}_{2}$-emission for electricity generation increases in this case by $50 \%$.

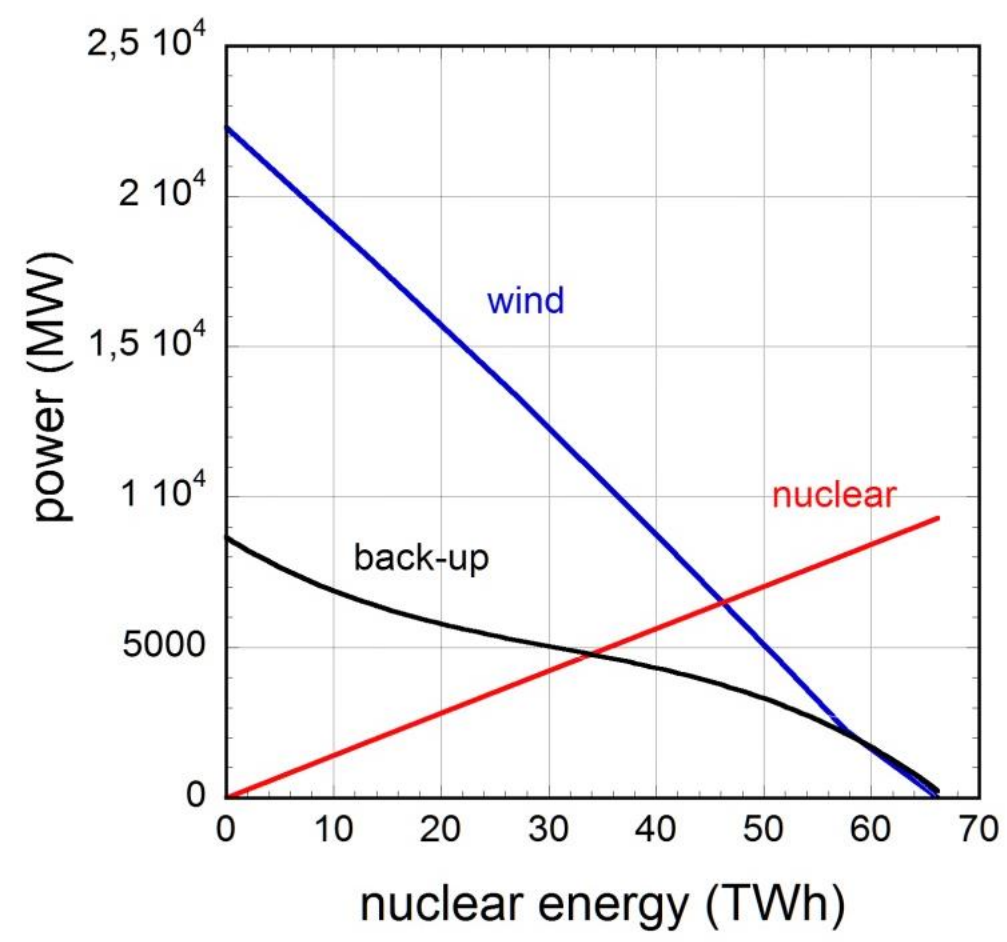

Figure 7. The power mix of the three constituents - wind, nuclear and back-up power is shown when the nuclear energy contribution is varied from the present level (63 TWh) down to zero.

\section{Acknowledgements}

Harry Frank, Dick Hedberg and Lennart Söder are acknowledged for valuable discussions on the possible developments of the Swedish electricity system. 


\section{References}

[1] http://www.svk.se/aktorsportalen/elmarknad/statistik/?category=\&modid=5146\&page=2\#5146; xls file: Förbrukning och tillförsel per timme, 2013.

[2] F. Wagner "Features of an electricity supply system based on variable inpul" EPJ Web of Conferences 5401009 (2013).

F. Wagner "Electricity generation by intermittent sources", proceedings of the Joint EPSSIF International School on Energy 2014, Course II - Energy: basic concepts and forefront ideas, 17 - 23 July 2014 - Villa Monastero - Varenna, Italy ed. L. Cifarelli and F. Wagner, p143.

[3] F. Wagner "Electricity by intermittent sources: An analysis based on the German situation 2012' Eur. Phys. J. Plus 129, 20 (2014).

[4] D. Grand, C. Le Brun and R. Vidil "Transition énergétique et mix électrique : les énergies renouvelables peuvent-elles compenser une réduction du nucléaire?' La Revue de l'Energie 619 (2014).

[5] D. Grand, C. Le Brun and R. Vidil "Intermittence des énergies renouvelables et insertion dans le mix électrique" accepted for publication in Techniques de l'Ingénieur, 2015.

[6] F. Romanelli "Strategy for the integration of intermittent renewable energy sources into the electrical system", accepted for publication in Europhysics Journal Plus.

[7] F. Wagner "Considerations for an EU-wide use of renewable energies for electricity generation" Eur. Phys. J. Plus 129, 219 (2014).

[8] IEA Technical Report: Wind Task 24 "Integration of Wind and Hydropower Systems" NREL/TP-5000-50181, December 2011.

[9] L. Söder "Possibilities for Balancing Wind Power Variations" http://www.divaportal.org/smash/get/diva2:467461/FULLTEXT01.pdf. 